\title{
POTENCIALIDADES DAS REGIÕES BRASILEIRAS PARA INSTALAÇÃO DE UMA FÁBRICA DE CELULOSE ${ }^{1}$
}

\begin{abstract}
Dario Orlandini², Elizabeth Neire da Silva ${ }^{3}$, Sebastião Renato Valverde ${ }^{4}$ e José Mauro Gomes ${ }^{4}$
RESUMO - Procurou-se neste estudo, com base na teoria de localização, classificar o território brasileiro segundo o potencial para atender às exigências de uma fábrica de celulose com produção anual de $1.000 .000 \mathrm{t} \mathrm{ano}^{-1}$. Consideraram-se quatro exigências mínimas do empreendimento para serem os indicadores em potencial. A sobreposição de todos os mapas forneceu regiões com valores de 0 a 4, sendo classificadas como inviável (0), de baixo potencial (1), de médio potencial (2), de bom potencial (3) e de excelente potencial (4) para a implantação da fábrica. A análise final para o território nacional possibilitou identificar 30,47\% de suas terras como áreas de excelente potencial para instalação de fábrica de celulose, 34,36\% como de bom potencial, 11,54\% como de médio, 23,63\% de baixo potencial e $0 \%$ como inviável. Concluiu-se, principalmente, que o Brasil é dotado de grande potencial para atrair grande parte da mudança do eixo da produção mundial de celulose do hemisfério Norte para o hemisfério Sul, o que poderia alavancar a economia da região com inúmeras melhorias ambientais.
\end{abstract}

Palavras-chave: Fábrica de celulose, Teoria da localização e Setor florestal.

\section{POTENTIALITIES OF BRASILIAN REGIONS FOR CELLULOSE PLANT SETLEMENT}

\begin{abstract}
The objective of this study was to classify, based on localization theory, the Brazilian territory to its potential to attend the demands of a cellulose plant with annual production of 1.000.000 year $^{-1}$. Four minimal requirements of the enterprise were considered for being potential indicators. The superposition of all maps showed regions with values ranging from 0 to 4 , being classified as unviable (0), potentially low (1), potentially medium (2), good (3) and potentially excellent (4) for setting up the enterprise. The final analysis for the national territory enabled to identify $30.47 \%$ of its land as potentially excellent areas for setting up a cellulose plant, $34.36 \%$ as satisfactory potential, $11.54 \%$ as average, $23.63 \%$ as potentially low and $0 \%$ unviable. Thus, it is concluded that Brazil is endowed with great potential to attracting great part of the change in the axis of the world cellulose production from the Northern to Southern Hemispheres. Besides, which could impeling the regional economy with countless environmental improvements.
\end{abstract}

Keywords: Pulp mill, Location theory, Forest sector and Site location.

\section{INTRODUÇÃO}

Com a crescente demanda do mercado mundial por celulose, ser competitivo tornou-se uma questão de sobrevivência. À medida que se descobrem vantagens competitivas em outras regiões, o segmento da indústria tende a migrar seus investimentos.
A mudança no eixo de produção de celulose do Hemisfério Norte para o Sul vem sendo observada desde a década de 1970 e tem ocorrido de forma mais intensiva nos últimos anos. A América do Norte perdeu cerca de $22 \%$ e a Europa Ocidental 5\% na participação do mercado global. Enquanto isso a América Latina aumentou sua produção de celulose de 8 para $24 \%$

\footnotetext{
${ }^{1}$ Recebido em 12.01.2010 e aceito para publicação em 02.05.2011.

${ }^{2}$ Agroflor Engenharia e Meio Ambiente - Dr. Ciências Florestais pela UFV. E-mail: <dorlandini@agroflor.com.br>.

${ }^{3}$ Universidade Federal do Espírito Santo, UFES, Brasil. E-mail: <elizabeth@cca.ufes.br>.

${ }^{4}$ Departamento de Engenharia Florestal, Universidade Federal de Viçosa, UFV, MG, Brasil. E-mail: <valverde@ufv.br>.
} 
(VIEIRA; SALUM, 2007). Ao manter a taxa média de crescimento anual das exportações de celulose de 1989 a 2002, o Brasil ultrapassará em 2010 a Suécia, em 2017 os EUA e em 2035 o Canadá (VALVERDE et al., 2006).

Dentro desse cenário de expansão da produção e da busca por competitividade, o Brasil é avaliado por experientes profissionais como um dos países que possuem as melhores condições para atrair investimentos de tais empreendimentos.

Enquanto as florestas brasileiras produzem madeira de eucalipto para celulose com aproximadamente sete anos, os principais concorrentes o fazem nas mesmas condições com mais de 50 anos (LEITE, 2007). Em média, as plantações de eucalipto no Brasil apresentam Incremento Médio Anual (IMA) de $40 \mathrm{~m}^{3} \cdot \mathrm{ha}^{-1}$. ano-1 (ZOGBI, 2007), podendo chegar até $63,5 \mathrm{~m}^{3} \cdot \mathrm{ha}^{-1} \cdot$ ano $^{-1}$, dependendo do material genético e das condições climáticas (GOMES; PACHECO, 1994).

A tecnologia brasileira de produção de florestas é uma das mais avançadas do mundo. A disponibilidade de terras para a atividade florestal é imensa devido à extensão territorial que possui, e a quantidade de área disponível para plantios vem sendo considerada por diversos pesquisadores como a maior do planeta.

O país poderá ser beneficiado com as inúmeras vantagens que os reflorestamentos e as indústrias do setor poderão trazer e já oferecem, como a diminuição da pressão por florestas nativas (área plantada: 5,2 milhões, sendo quase dois milhões para celulose e papel), os empregos gerados: 4,1 milhões (10,4\% PEA), entre outros (MADRUGA, 2007).

Com base na necessidade dos empresários do setor de celulose em se tornarem competitivos no mercado internacional e tendo conhecimento de que o Brasil possui inúmeras características favoráveis para desenvolvimento do setor florestal, justificou-se o desenvolvimento deste estudo visando classificar o potencial brasileiro para suprir as exigências de uma fábrica de celulose com produção mínima de 1.000.000 t/ano de polpa de fibra curta, seguindo uma tendência atual do porte das novas indústrias a serem instaladas.

\section{MATERIAL E MÉTODOS}

\subsection{Classificação do potencial regional para instalação de fábrica de celulose}

Todo empreendimento a ser instalado exige uma série de fatores econômicos, sociais e ambientais, e a existência ou a inexistência de algum deles em condições adequadas indicam se a região possui ou não potencial para comportar o empreendimento. Assim, optou-se por classificar regiões brasileiras segundo o potencial para atender às exigências do empreendimento estudado (fábrica de celulose com produção anual de um milhão de toneladas). A avaliação do potencial de regiões para atender às exigências de uma fábrica de celulose apoiou-se na Teoria de Localização, em que cada fator exerce uma força para locação ótima do empreendimento. Optou-se por estudar quatro exigências da fábrica, consideradas como indicadores do potencial de uma região para a instalação do empreendimento.

Os indicadores de potencial considerados para este estudo, com base em discussões com especialistas e em consultas à literatura, foram:

1 - Distância de fábrica de celulose já existente.

2 - Distância de terminais portuários marítimos e fluviais. 3 - Distância de rodovias e ferrovias.

4 - Incremento Médio Anual (IMA) potencial.

Definidos os indicadores de potencial a serem utilizados no estudo, foi necessário atribuir valores (pesos) para regiões que atenderam aos indicadores e para aquelas que não atenderam, permitindo, assim, a classificação do território nacional, para cada indicador, com áreas de valor 0 (menor potencial) e com valor 1 (maior potencial). Utilizou-se um mapa do território nacional contendo Ferrovias, Rodovias, Localização das Fábricas de Celulose e Localização dos Terminais Portuários Marítimos e Fluviais (MMA, 2007).

O passo seguinte, após a elaboração do mapa com áreas de valor 0 e de valor 1 para cada indicador, foi realizar o somatório de todas as áreas de cada mapa gerado.

A sobreposição (somatório) dos quatro mapas originou um único mapa contendo regiões de valores $0,1,2,3$ e 4, sendo as regiões de valor 0 inviável, de valor 1 de baixo potencial, de valor 2 de médio potencial, 
de valor 3 de bom potencial e de valor 4 de excelente potencial para instalação de fábrica de celulose com produção de 1.000.000 de t/ano.

Após a elaboração do mapa final, uma análise empírica foi realizada para refinar o resultado, eliminando discrepâncias. Os critérios utilizados para a atribuição de valores a cada indicador de potencial seguem nos tópicos subsequentes.

\subsubsection{Distância das fábricas de celulose}

É fato que aumento na demanda por terras faz seu valor aumentar. Dessa forma, foi possível inferir que a proximidade com outras fábricas ou outros empreendimentos que exigem áreas para o plantio de florestas pode ser fator limitante para instalação de nova fábrica, uma vez que implica aumento da demanda por terras com consequente incremento do seu valor de aquisição, resultando em impacto direto no custo final do produto.

Considerando que para uma produtividade de $40 \mathrm{~m}^{3} \mathrm{ha}^{-1} \mathrm{ano}^{-1}$ é preciso aproximadamente $4 \mathrm{~m}^{3}$ de madeira para a produção de uma tonelada de celulose, seria necessária, portanto, uma área de cerca de 100.000 ha de plantio - que pode ser própria ou de terceiros (Fomento Florestal) - para atender a uma demanda de matéria-prima para produção anual de 1.000.000 de $\mathrm{t}$ ano ${ }^{-1}$ de celulose. Além disso, devem ser observadas as Áreas de Preservação Permanente (APP) e de Reserva Legal, que, para algumas regiões (como é o caso da Amazônia), significa destinar até mais que $80 \%$ (RL e APP) da área da propriedade para cumprimento da legislação.

A fim de evitar o aumento da demanda por terras e seu inflacionamento, as áreas encontradas próximas a fábricas foram consideradas como áreas de menor potencial para instalação de outra fábrica. Para isso, definiu-se um raio de segurança de fábricas de celulose já existentes, ou seja, as áreas dentro do raio definido foram consideradas de menor potencial (valor 0) para instalação de fábricas de celulose e fora dessas áreas, consideradas de maior potencial (valor 1). A partir dos pontos de localização das fábricas de celulose, criou-se um buffer com a distância de $100 \mathrm{~km}$ para fábricas com produção anual entre 350 mil e 700 mil t ano-1 150 km para fábricas com produção anual igual e entre $700 \mathrm{mil}$ e 1 milhão t ano-1 e $200 \mathrm{~km}$ de raio para fábricas com produção anual acima de 1 milhão de toneladas por ano de celulose.

\subsubsection{Distância de terminais portuários marítimos e fluviais}

O custo de transporte da matéria-prima ao mercado consumidor é uma variável importante a ser avaliada na localização de atividades econômicas (OLIVEIRA et al., 1993). Considerando que, em 2006, 54,57\% da celulose brasileira foi destinada ao mercado internacional e a projeção era de que esse valor aumentasse a cada ano, adotou-se um raio de distância dos terminais portuários para definir as regiões de maior e de menor potencial para a instalação do empreendimento em estudo. Dessa forma, áreas que estivessem além dessa distância definida foram consideradas de menor potencial por elevar o custo da celulose e as que se encontravam dentro desse alcance, consideradas de maior potencial.

Considerando que o transporte da celulose para o mercado internacional é realizado por meio de transporte marítimo (navios), verificou-se que para transportar a celulose até os terminais portuários dois meios eram mais utilizados: o ferroviário e o rodoviário. Assim, longas distâncias por ferrovia e rodovia até os portos elevavam o preço da celulose. Verificou-se também que os navios que realizavam transporte por hidrovias não eram os mesmos que faziam o transporte marítimo, portanto a distância para transporte terrestre até os portos fluviais teve que ser menor que a distância para os portos marítimos, pois englobavam também os custos do transporte hidroviário.

A distância viável para o transporte de polpa de celulose depende de uma série de fatores, como o custo da madeira, que interfere no custo final da polpa, do modal de transporte utilizado, das condições das vias de transporte, de pedágios e de inúmeros outros fatores. No entanto, é consenso dizer que, quanto mais distante do porto, menor o potencial para instalação de uma fábrica de celulose.

Para efeito deste estudo, utilizaram-se como proposição as distâncias lineares até os terminais portuários como indicadores de potencial para a instalação da fábrica, definindo áreas de maior e de menor potencial. Neste item, o primeiro passo foi a listagem de todos os portos brasileiros, marítimos e fluviais. Tal procedimento considerou uma distância para definir o potencial das áreas e criou um buffer, em que: as vias externas a ele foram consideradas regiões de menor potencial para instalação do empreendimento 
em análise, sendo a elas atribuído o valor 0; já as regiões dentro do buffer foram consideradas de maior potencial, sendo a essas conferido o valor 1 .

\subsection{Distância de rodovias e ferrovias}

Levou-se em consideração que uma fábrica não necessariamente deveria ser localizada à margem das rodovias e das ferrovias, pois poderia ser construído um acesso no momento de sua instalação. Utilizou-se como proposição o fato de que o empreendimento poderá ser implantado até uma distância de 100 km da ferrovia ou da rodovia já existente, pois o custo da construção do acesso às vias pode ser incorporado ao de implantação do empreendimento.

Criou-se um buffer com essa distância, definida a partir das vias. Foram atribuídos os valores 1 (áreas de menor potencial) para as áreas onde as rodovias e ferrovias se distanciam em até $100 \mathrm{~km}$, e valores 0 (áreas de menor potencial) para áreas em que as ferrovias e rodovias estão localizadas a mais de $100 \mathrm{~km}$.

\subsubsection{Incremento médio anual potencial para reflorestamento}

Considerando que a produção em larga escala dos povoamentos das atuais fábricas de celulose ultrapassa um Incremento Médio Anual (IMA) de $35 \mathrm{~m}^{3} \mathrm{ha}^{-1} \mathrm{ano}^{-1}$, estabeleceu-se esse limite para classificação de potencial regional para instalação da fábrica de celulose.

Para classificar as regiões brasileiras segundo o IMA potencial, utilizaram-se informações geradas pelo software 3 PG fornecidas pelo Departamento de Solos da Universidade Federal de Viçosa (DPS/UFV). O cálculo do IMA potencial pelo software 3 PG levou em consideração a pluviosidade, a fertilidade e a estrutura do solo. As simulações de produtividade foram processadas com base na parametrização obtida para diferentes clones de eucalipto, a partir de 1 ano de idade. Nessas simulações, foi considerado um solo de textura média, com Capacidade de Água Disponível (CAD) de 125 mm e fertilidade plena, ou seja, sem restrições físico-químicas. As regiões com produção inferior a $35 \mathrm{~m}^{3} \mathrm{ha}^{-1} \mathrm{ano}^{-1}$ foram consideradas de menor potencial, sendo-lhes atribuído o valor 0 , e regiões com IMA acima dessa capacidade, como as de maior potencial, às quais foi atribuído o valor 1 .

\section{RESULTADOS}

\subsection{Regiões com potencial para instalação da fábrica de celulose}

A verificação do potencial de regiões para atender às demandas de uma fábrica de celulose com produção de 1.000.000 t/ ano, segundo os indicadores de potencial utilizados, encontra-se a seguir.

\subsubsection{Regiões potenciais segundo distâncias entre as fábricas de celulose}

A existência de 12 fábricas de celulose no Brasil com produção anual acima de 350 mil toneladas e mais uma em projeto levou à identificação de regiões de menor potencial (valor 0) para o entorno das fábricas e daquela em formação (Figura 1) e de maior potencial (valor 1 ) as regiões distantes.

As regiões de menor potencial correspondem a 6,52\% da área do território nacional (555.124,12 km²), sendo todo o restante do território (93,48 \%) de áreas de maior potencial (valor 1 ).

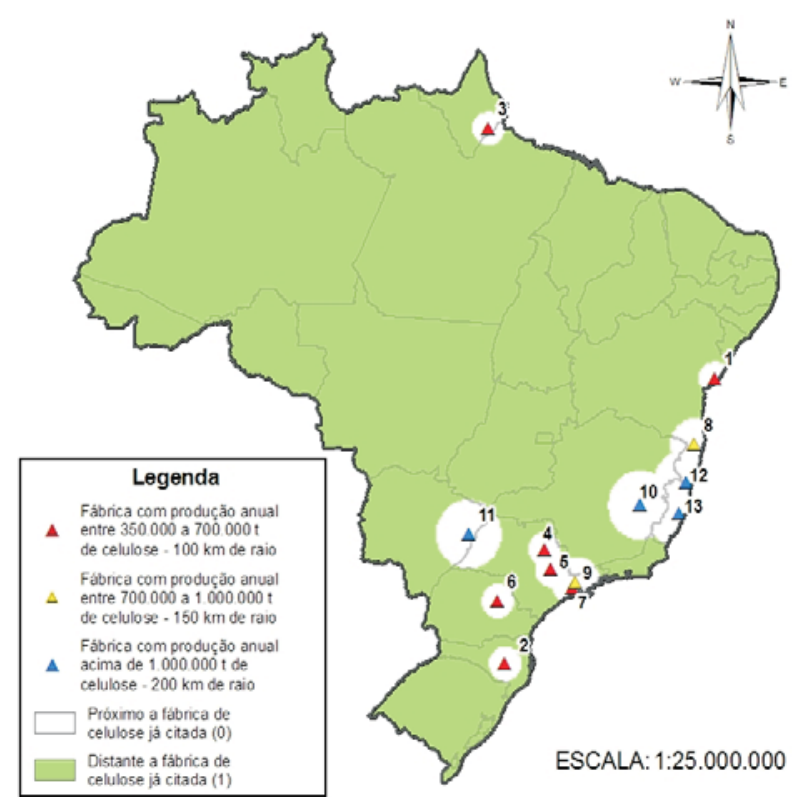

Figura 1 - Potencial para instalação de fábricas de celulose com produção anual de $1.000 .000 \mathrm{t}$, segundo a "distância de fábrica de celulose".

Figure 1 - Potential for installation of pulp mills with annual production of 1,000,000 t., according to "distance from pulp mill". 


\subsubsection{Regiões potenciais segundo distâncias dos terminais portuários}

O indicador de potencial "distância de terminais portuários” permitiu verificar que 55,31\%(4.709.955,02 km²) do território brasileiro encontra-se em áreas de maior potencial para instalação de fábricas de celulose com produção anual de 1.000.000 t/ano. Essa área estende-se por todo o litoral e no entorno de alguns trechos dos principais rios navegáveis, como os rios Amazonas (Estados do Amazonas e do Pará), São Francisco (Estados de Minas Gerais e Bahia), Paraná (Divisa do Estado de São Paulo com Mato Grosso do Sul e divisa de Santa Catarina com a Argentina), Madeira (Estado de Rondônia), Mamoré (divisa do Estado de Rondônia com a Bolívia), Paraguai (Estado do Mato Grosso do Sul com a Bolívia) e Cuiabá (Estado do Mato Grosso), conforme mostrado na Figura 2.

\subsubsection{Regiões potenciais segundo distâncias de rodovias e ferrovias}

O resultado da análise de distância de rodovias e ferrovias (Figura 3) permitiu identificar as regiões de maior (valor 1) e de menor potencial (valor 0) para instalação de fábricas de celulose, distantes $100 \mathrm{~km}$ das malhas rodoviária e ferroviária. Esse diagnóstico evidencia o grande potencial das Regiões Sul, Sudeste, CentroOeste e Nordeste em atender às necessidades de transporte de uma fábrica de celulose. Observou-se uma área total

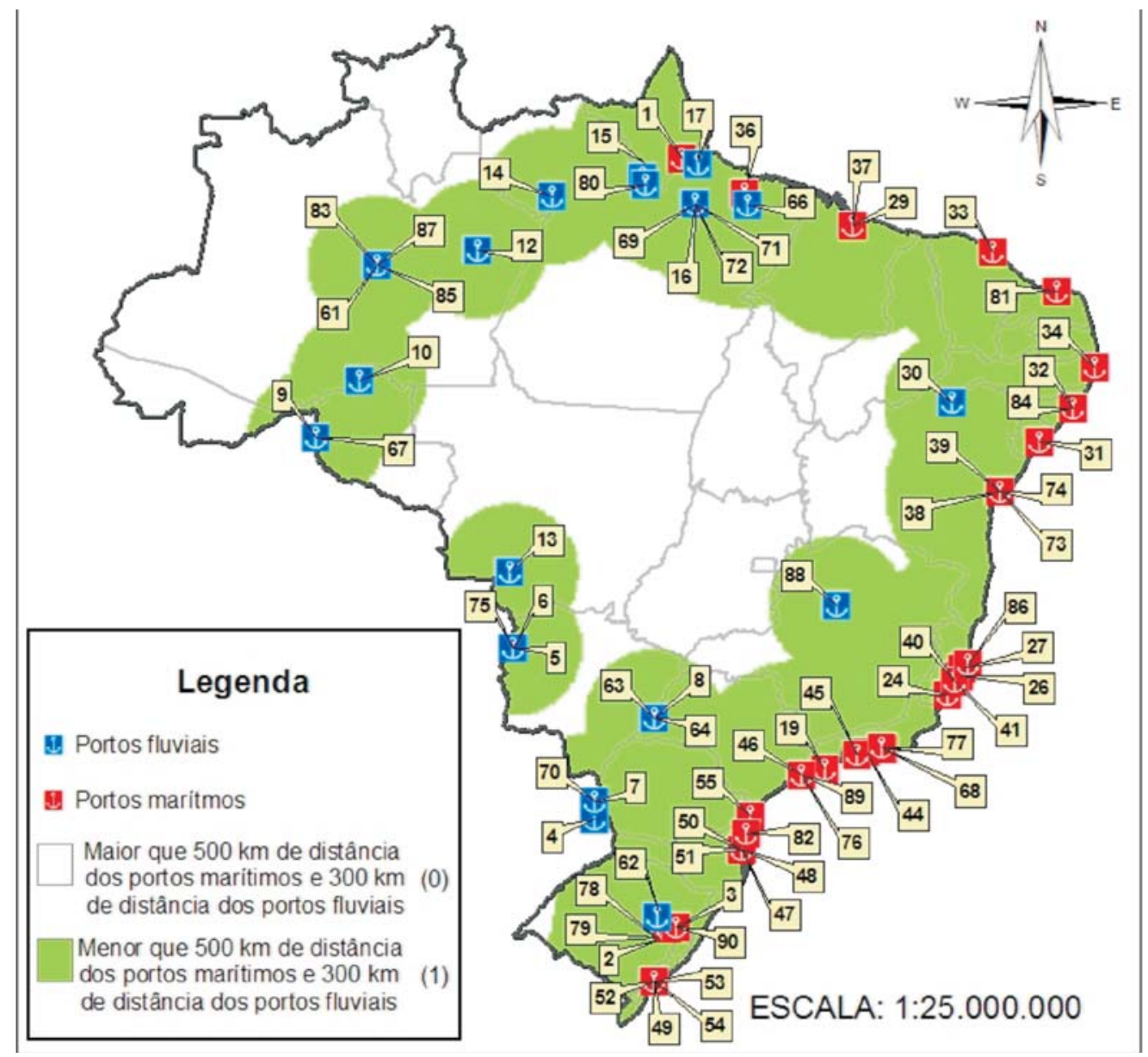

Figura 2 - Potencial para instalação de fábricas de celulose com produção anual de 1.000 .000 t./ano, segundo as distâncias dos terminais portuários marítimos e fluviais.

Figure 2 - Potential for settlement of pulp mills with annual production of 1,000,000 tons / year, according to distances of port terminals and inland sea. 


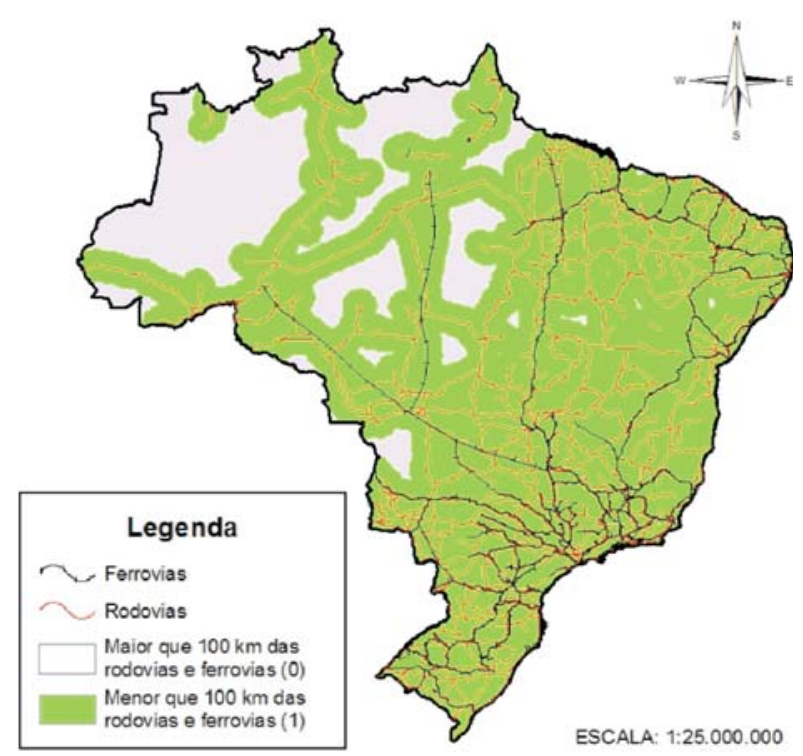

Figura 3 - Potencial para instalação de fábricas de celulose com produção anual de 1.000.000t, segundo a distância de rodovias e ferrovias.

Figure 3 -Potential for installation of pulp mills with annual production of 1,000,000t, according to distance from roads and railways.

de 6.904.802,66 km² do território nacional (81,09\%) como de maior potencial para instalação do empreendimento, enquanto a Região Norte apresenta o menor potencial, com uma área de 1.610.073,34km², ocupando 18,91\% do território nacional.

\subsubsection{Regiões potenciais segundo o incremento médio anual}

A identificação de áreas com IMA potencial abaixo de $35 \mathrm{~m}^{3} / \mathrm{ha} /$ ano (valor 0 ) permitiu constatar que 23,62\% (2.011.488,74 km²) do território nacional possui baixo potencial para instalação de fábricas de celulose com produção anual de 1.000.000 t/ano (Figura 4).

\subsubsection{Regiões potenciais segundo todos indicadores analisados}

O somatório das áreas de valores 0 e 1 , identificadas nas análises dos quatro indicadores de potencial distância de fábricas de celulose, distância de terminais portuários, distância de rodovias e ferrovias e IMA potencial - resultou em um mapa (Figura 5) com 30,47\% (2.594.687,45 km²) do território nacional como áreas de excelente potencial (valor 4), 46,69\% (3.975.430,72 km²)

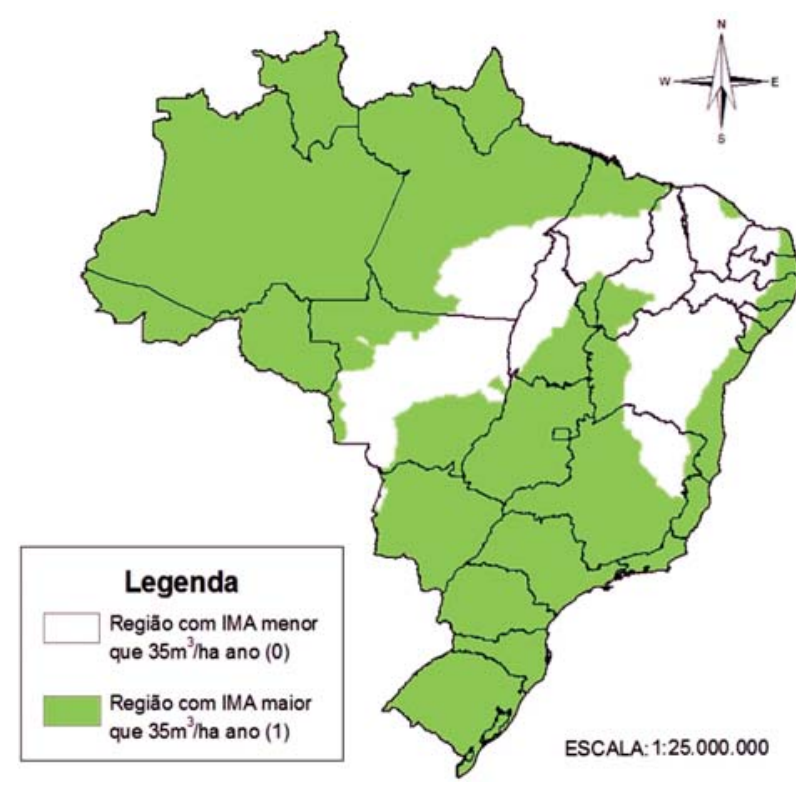

Figura 4 - Potencial para instalação de fábricas de celulose com produção anual de 1.000 .000 t, segundo o IMA potencial.

Figure 4-Potential for settlement of pulp mills with annual production of 1,000,000 t according to potential AIM.

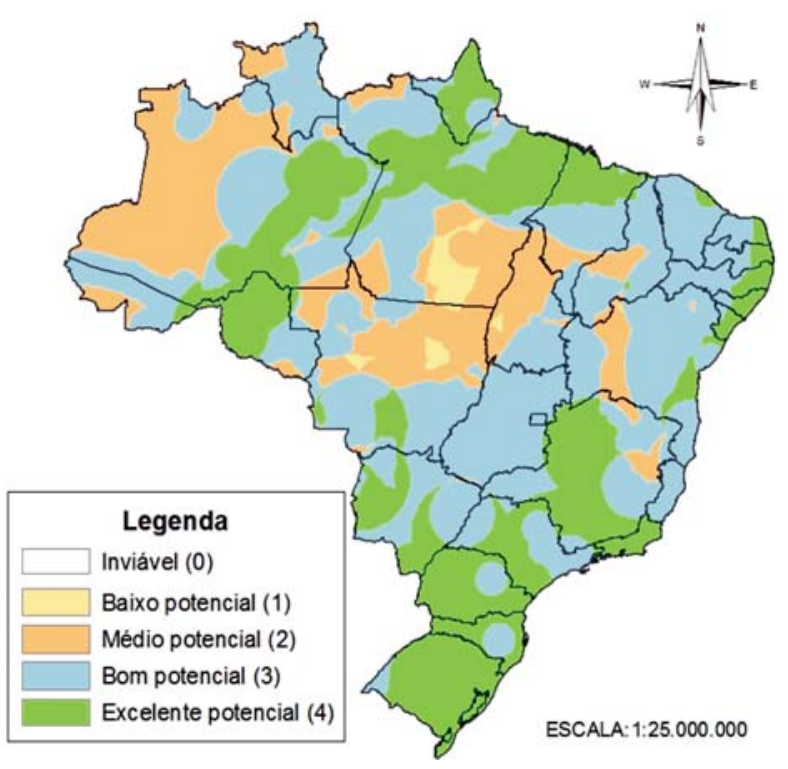

Figura 5 - Potencial para instalação de fábricas de celulose com produção anual de $1.000 .000 \mathrm{t}$, segundo os quatro indicadores de potencial.

Figure 5 - Potential for settlement of pulp mills with annual production of 1,000,000t, according to four indicators of potential. 
como áreas de bom potencial (valor 3), 21,45\% (1.826.333,16 km²) como áreas de médio potencial (valor 2)e 1,39\% (118.424,68 km²) como área de potencial ruim (valor 1). Nenhuma área foi definida como área inviável (valor 0) para a instalação do empreendimento, pelos procedimentos utilizados.

\section{DISCUSSÕES}

Analisando as regiões potenciais segundo as distâncias entre as fábricas de celulose, observou-se que as áreas de menor potencial (valor 0) concentraram-se, principalmente, nas proximidades do litoral. Sua maior concentração se dava nas Regiões Sudeste e Sul, o que criou uma grande área de menor potencial para instalação de fábricas de celulose, sobretudo na Região Sul. Três principais motivos podem ter propiciado essa concentração de fábricas:

1 - A distância de transporte é fator importante no custo do produto. As fábricas concentravam-se nas proximidades do litoral, buscando a proximidade com os portos.

2 - A proximidade com centros mais desenvolvidos facilita a utilização de mão de obra qualificada tanto para produção quanto para manutenção.

3 - Regiões com boas condições edafoclimáticas são mais propícias para a instalação dos povoamentos florestais.

O indicador de potencial "distância de terminais portuários” permitiu verificar que o centro do Brasil e o extremo noroeste são áreas que apresentam menor potencial para instalação de fábricas de celulose devido à distância de terminais portuários. É importante ressaltar que este estudo apresenta as regiões potenciais segundo a existência de terminal portuário, porém a maioria deles atualmente embarca outro tipo de produto. Deve-se deixar claro que, para o embarque de celulose, deverá haver negociações e, ou, adaptações dos terminais portuários.

O resultado da análise de distância de rodovias e ferrovias permitiu evidenciar o grande potencial das Regiões Sul, Sudeste, Centro-Oeste e Nordeste em atender à necessidade de transporte de fábrica de celulose. Como se observa nos resultados, há imensa área do território nacional, como de maior potencial para instalação do empreendimento em análise, pois a grande malha rodoviária e algumas ferrovias concentram-se nas regiões mais desenvolvidas. Já a Região Norte apresenta o menor potencial de instalação de fábrica de celulose, segundo o indicador de potencial distância de rodovias e ferrovias.

Em relação ao fator IMA potencial, observou-se que as menores áreas potenciais concentravam-se nas regiões mais secas, localizadas principalmente no Nordeste do Brasil, centro do Mato Grosso, Sudeste do Pará e Norte de Goiás.

O somatório das áreas identificadas nas análises dos quatro indicadores de potencial, pelos procedimentos utilizados, indicam que as áreas de baixo potencial encontravam-se localizadas, principalmente, onde o IMA potencial era menor que $35 \mathrm{~m}^{3} / \mathrm{ha}$ /ano, ou seja, no Norte do Centro-Oeste e no Sudeste do Norte, onde somente um indicador de potencial foi atendido pela região: a distância da fábrica de celulose. As regiões de médio potencial também se encontravam no Norte do Centro-Oeste e no Sudeste do Norte, localizando-se também no Noroeste do Norte, que é carente de malha viária e distante de terminais portuários. As regiões classificadas como de bom e de excelente potencial ocupavam grande parte do território e estavam distribuídas ao longo de quase todo o país, em pequenas e grandes áreas.

Já as áreas de excelente potencial concentravam-se, principalmente, nas Regiões Sul, Sudeste e Norte do país.

Uma análise empírica dos resultados obtidos pôde fornecer uma visão mais refinada, a começar pelas áreas de IMA potencial abaixo de $35 \mathrm{~m}^{3}$ /ha/ano, uma vez que, apesar de existirem vários critérios que as classificam como de potencial melhor (próxima a rodovias e ferrovias, próxima a terminais portuários, distante de fábricas de celulose), o IMA é um fator fundamental a ser considerado. Aumentá-lo significa ter que trabalhar com variáveis do tipo pluviosidade e estrutura do solo, ou seja, são variáveis de difícil manipulação.

Mesmo as regiões que contemplaram todos os indicadores foram, assim, consideradas de baixo potencial quando localizadas em áreas com IMA menor que $35 \mathrm{~m}^{3}$ /ha/ano. Portanto, as áreas de baixo potencial classificadas anteriormente, que ocupavam 1,39\% do território nacional, passam, agora, a ocupar 23,63\% (2.011.488,74 km²) e estão localizadas no sudeste da Região Norte, em parte do Noroeste da Região Centro- 
Oeste, quase na totalidade da região Nordeste e no Nordeste do Sudeste. As áreas de médio potencial também sofreram alterações e passaram a ocupar $11,54 \%$ (982.638,99 km²) do território nacional; as de bom, 34,36\% (2.926.081,75 km²); e as de excelente potencial e inviáveis continuaram com os mesmos 30,47 e 0\%, respectivamente.

Apesar de existirem porções de bom e excelente potencial na região amazônica, algumas considerações devem ser tecidas. A área de reserva legal nessa região compreende $80 \%$ da área total da propriedade, elevando-se o total da área a ser adquirida para o reflorestamento.

Outra consideração importante também é em relação ao Pantanal, proibido de uso por ser considerado como Áreas de Preservação Permanente, sendo assim considerado como inviável para a instalação do empreendimento analisado.

\section{CONCLUSÕES}

Os resultados podem apoiar a busca por investimentos no setor de celulose e alertar os administradores sobre as oportunidades de negócio para as regiões, uma vez que demonstram o grande potencial brasileiro para a instalação de fábricas de celulose.

Existem inúmeros outros fatores que influenciam no potencial das áreas para instalação de fábricas de celulose e podem ser objeto de novos estudos, como: áreas inviáveis para reflorestamento por constituírem unidades de conservação, áreas particulares restritas de uso, zonas de amortecimento de Unidades de Conservação, custo elevado da terra em algumas regiões etc.

\section{REFERÊNCIAS}

BANTEL, C. A. O ensino da silvicultura e a demanda por profissionais no Brasil. Revista da Madeira, n.106, julho, 2007.
BRASIL. Ministério do Meio Ambiente. Disponível em:< http://www.mma.gov.br/> Acesso em: 13 de mar. 2007.

GOMES, F. S.; PACHECO, R. M. Clonagem de Eucalipto na Jarí. In: REUNIÃO

\section{REGIONAL SOBRE CLONAGEM}

INTENSIVA EM EUCALYPTUS, 1994, Aracruz. Anais... Aracruz: IPEF, 1994. p.67-68.

INSTITUTO BRASILEIRO DE GEOGRAFIA E ESTATÍSTICA - IBGE. Anuário Estatístico do Brasil. Disponível em: <http:// www.ibge.gov.br> Acesso em: 20 nov. 2007.

LEAL FILHO, N. Caracterização do banco de sementes de três estágios de uma sucessão vegetal na Zona da Mata de Minas Gerais. 1992. 116f. Dissertação (Mestrado em Ciência Florestal). Universidade Federal de Viçosa, Viçosa, MG, 1992.

LEITE, N. B. Brasil: uma potência florestal emergente. Revista Opiniões, jun/ago., p.10, 2007.

MADRUGA, V. O mercado brasileiro no cenário mundial de celulose. Revista Opiniões. jun.ago., p.14., 2007.

VALVERDE, S. R.; SOARES, N. S.; SILVA, M. L. Desempenho das exportações brasileiras de celulose. Revista Árvore, v.30, n.6, p.1017-1023, 2006.

VIEIRA, G. A.; SALUM, J. J. A mudança da produção do norte para o sul do planeta. Revista Opiniões. jun.-ago., p.24., 2007.

ZOGBI, O. E. Brasil: destino preferencial para o setor de celulose e papel. Revista Opiniões. jun.ago., p.8, 2007. 